\title{
Human infections with verocytotoxin-producing Escherichia coli O157 - 10 years of E. coli O157 serodiagnosis
}

\author{
Henrik Chart and Thomas Cheasty
}

Correspondence

Henrik Chart

henrik.chart@hpa.org.uk

Received 25 May 2008

Accepted 15 July 2008

\author{
Laboratory of Enteric Pathogens, Department of Gastrointestinal, Emerging and Zoonotic \\ Infections, Centre for Infections, Health Protection Agency, 61 Colindale Avenue, London NW9 \\ 5EQ, UK
}

From 1997 to 2007, the Laboratory of Enteric Pathogens (LEP), Health Protection Agency, UK, received sera from 2148 patients for testing for antibodies to the LPS of verocytotoxin-producing Escherichia coli (VTEC) O157. A total of 676 (31.5\%) sera had antibodies binding the LPS of E. coli $\mathrm{O} 157$ and the majority of patients were below the age of 10 years, a trend observed for both males and females. Antibody-positive patients had haemolytic uraemic syndrome (HUS) in $79.3 \%$ of cases and most of these presented with the atypical (D-) form of HUS. Nine patients were shown to have antibodies to the LPS of E. coli belonging to serogroups O26 (4), O103 (2), $\mathrm{O} 111$ (1) and $\mathrm{O} 145$ (2) and one patient had antibodies to the somatic antigens of both $E$. coli O26 and O103. The serodiagnosis of infections with E. coli O157 and other VTEC continues to be an important adjunct to bacteriology. Where clinicians suspect the involvement of a VTEC in disease, patients' sera should be submitted to the LEP for analysis without delay.

\section{INTRODUCTION}

Verocytotoxin-producing Escherichia coli (VTEC), and particularly strains of serotypes $\mathrm{O} 157: \mathrm{H} 7$ and $\mathrm{O} 157: \mathrm{H}-$ (VTEC O157), continues to be a significant cause of human disease in the UK (Lynn et al., 2005). E. coli O157 and other VTEC cause diseases with symptoms including diarrhoea, bloody diarrhoea and/or haemolytic uraemic syndrome (HUS). Typically infections involve episodes of non-bloody diarrhoea followed by bloody diarrhoea (Mead \& Griffin, 1998) with some $10-15 \%$ of patients developing HUS (Tarr et al., 2005). This prodrome of diarrhoea prior to onset of HUS has been termed 'typical' or $(D+)$ HUS. Patients may develop HUS without a prodrome of diarrhoea and this clinical presentation has been termed 'atypical' or (D-) HUS (Karmali et al., 1985).

The surveillance of diseases caused by VTEC, and in particular VTEC O157, is essential for the monitoring and control of infections caused by these bacteria, and procedures have been developed to isolate VTEC and/or detect the genes encoding the toxins that they express (Chart, 2000). Surveillance has shown that, since 1982, the number of strains of VTEC O157 received by the Health Protection Agency, Laboratory of Enteric Pathogens (LEP), has increased from one isolation in 1982 to peak isolations of 1087, 1084 and 1003 in 1997, 1999 and 2006, respectively

Abbreviations: HUS, haemolytic uraemic syndrome; LEP, Laboratory of Enteric Pathogens; VTEC, verocytotoxin-producing Escherichia coli.
(Lynn et al., 2005; http://www.hpa.org.uk/infections/topics_ az/ecoli/O157/data_ew.htm).

Isolating VTEC from patients' stools provides a definitive cause of infection and permits serotyping and toxin typing of isolates to be carried out for the purposes of surveillance. These VTEC isolates are usually present in patients' faeces for only a limited period of time and once viable VTEC is no longer available for bacteriology, alternative means of providing evidence of infection are required. Patients infected with VTEC produce serum and salivary antibodies to their respective somatic or LPS antigens (Chart \& Jenkins, 1998, 1999; Jenkins \& Chart, 1999b; Chart et al., 2003). Based on these findings, the LEP was able to develop immunoassays to provide a primary serodiagnostic service. Patients' sera and saliva are screened for IgA-, IgG- and IgM-class antibodies to purified VTEC O157 LPS using the techniques of SDS-PAGE and immunoblotting (Chart \& Jenkins, 1999). The LPS of E. coli O157 has been shown to share epitopes with the LPS expressed by other bacteria (Chart \& Jenkins, 1999), and when assessing the role of $E$. coli $\mathrm{O} 157$ in a given infection, the results of serodiagnosis are considered in the light of possible antigenic crossreactions and the patients' symptoms.

In 2002, patients infected with E. coli $\mathrm{O} 157$ were shown to produce serum antibodies which bind to the R3 moiety of E. coli O157 core LPS (Chart et al., 2002a; Dalwai \& Chart, 2003). It was also demonstrated that the R3 core LPS was located on the core LPS of certain other serogroups of VTEC (Chart et al., 2004). Following these observations, all 
sera with antibodies binding to the R3 LPS core epitopes of O157 LPS were screened routinely for antibodies to LPS prepared from a panel of VTEC, comprising strains of VTEC belonging to serogroups of current importance in the UK and mainland Europe. For this study, these included LPS from E. coli O26, O55, O103, O111, O128 and O145. This panel was also used to screen sera from patients with HUS but who did not have serum antibodies to the E. coli O157 LPS.

In the present report, we describe the results of routine $E$. coli $\mathrm{O} 157$ serodiagnosis performed on sera received by the LEP over a 10 -year period. During this period, the LEP received 2148 sera of which $676(31.5 \%)$ had antibodies to E. coli O157. Of the 676 antibody-positive patients, a faecal isolate of E. coli O157 was obtained from only 17, such that for the remaining $659(97.5 \%)$ patients evidence of infection with $E$. coli $\mathrm{O} 157$ was provided solely by serology.

\section{METHODS}

The preparation of antigens and the analysis of patients' sera were performed using Clinical Pathology Accreditation UK approved standard operating procedures, developed within the LEP.

Sera. Sera were referred to the LEP from sending laboratories located in the UK. During the period from 6 November 1997 to 6 November 2007, sera were received from a total of 2148 patients. Details of age were provided for 1551 patients (mean $=23$ years 6 months; $\sigma=25$ years 2 months), and gender was provided for 2008 patients (892 males, 1116 females). An age was known for 710 male patients (mean $=21$ years 11 months; $\sigma=23$ years 11 months) and 850 female patients (mean age $=24$ years 10 months; $\sigma=26$ years 1 month).

Bacteria. VTEC O157:H- strain E32511 was used for the preparation of LPS expressing the O157 somatic antigens (Chart et al., 2002b). LPS was also prepared from strains of E. coli belonging to serogroups O26 (E36039), O55 (E40230), O103 (E50276), O111 (E52849), O128 (E41509) and O145 (E38938). All strains were from the culture collection held by the LEP. Bacteria were grown on horse blood agar $\left(37^{\circ} \mathrm{C}, 16 \mathrm{~h}\right)$.

LPS. For SDS-PAGE and immunoblotting, LPS was prepared by digesting whole bacteria with proteinase K (Chart et al., 1989). Bacteria were placed in pre-weighed Eppendorf tubes and the cells were suspended in SDS-PAGE sample buffer (Laemmli, 1970) to give a concentration of $1 \mathrm{mg}(30 \mu \mathrm{l})^{-1}$ prior to incubation at $100{ }^{\circ} \mathrm{C}$ for $10 \mathrm{~min}$. After cooling, samples were mixed with an equal volume of SDS-PAGE buffer containing $100 \mu \mathrm{g}$ proteinase $\mathrm{K}(30 \mu \mathrm{l})^{-1}$ (Sigma Chemical) prior to incubation at $60{ }^{\circ} \mathrm{C}$ for $1 \mathrm{~h}$.

SDS-PAGE and immunoblotting. SDS-PAGE was performed using an Atto mini-gel apparatus (Genetic Research Instruments) as described previously (Chart, 2003). Preparations containing $83 \mu \mathrm{g}$ digested cell mass were used per lane, and loaded onto gels comprising a stacking gel with $4.5 \%(\mathrm{w} / \mathrm{v})$ acrylamide and a separation gel with $12.5 \%(\mathrm{w} / \mathrm{v})$ acrylamide. Electrophoresis was performed (50 mAmp) for $30 \mathrm{~min}$ and profiles were transferred onto nitrocellulose paper (NCP) by immunoblotting (Chart et al., 1989; $0.50 \mathrm{Amp}, 1 \mathrm{~h}$ ). Profiles immobilized on sheets of NCP were blocked with $3 \%(\mathrm{w} / \mathrm{v})$ skimmed milk in PBS (milk-PBS; $30 \mathrm{~min}$ ) and reacted with $30 \mu \mathrm{l}$ serum in $5 \mathrm{ml}$ milk-PBS for $60 \mathrm{~min}$. After washing in PBSTween $(3 \times 10 \mathrm{~min})$, profiles were reacted with $5 \mu \mathrm{l}$ per lane of goat anti-human polyvalent Ig conjugated with alkaline phosphatase
(Sigma) in skimmed milk-PBS (60 min). After washing, as above, profiles were placed in substrate buffer $(0.1 \mathrm{M}$ Tris, $0.09 \mathrm{M} \mathrm{NaCl}$, $0.15 \mathrm{M} \mathrm{MgCl}_{2} \cdot 6 \mathrm{H}_{2} \mathrm{O}$ ) containing $45 \mu \mathrm{l}$ nitro blue tetrazolium (Sigma; $75 \mathrm{mg} \mathrm{ml}^{-1}$ in $70 \%$ aqueous dimethylformamide) and $35 \mu \mathrm{l} \mathrm{5-}$ bromo-4-chloro-3-indolyl phosphate. $\mathrm{Na}_{2}$ (Sigma; $50 \mathrm{mg} \mathrm{ml}^{-1}$ in deionized water).

\section{RESULTS AND DISCUSSION}

\section{Patients}

From November 1997 to November 2007, the LEP received sera from 2148 patients requiring E. coli O157 serodiagnosis. Patients had been reported as having experienced diarrhoea (407), bloody diarrhoea (143), HUS (557), vomiting (89) and/or pyrexia (24), and 25 cases had been fatal. Clinical details of patients' symptoms were not provided for 1188 (55.3\%) of patients. These details provide valuable information in the final assessment of the results of serodiagnosis and the absence of salient clinical data for over half of the patients in this study represents a constant problem.

\section{E. coli 0157 serodiagnosis}

Of the 2148 patients, $676(31.5 \%)$ had serum antibodies binding the LPS of E. coli O157, as detected by SDS-PAGE and immunoblotting (Chart \& Jenkins, 1999). These patients were considered 'antibody-positive' and as such were regarded as having been infected with a strain of $E$. coli O157. A total of 1462 patients were found not to have serum antibodies to the E. coli $\mathrm{O} 157$ somatic antigens. Of the 676 antibody-positive patients, 17 had E. coli $\mathrm{O} 157$ isolated from their stools, whilst for the remaining 659 patients $(97.5 \%)$, evidence of infection was detected by serology alone. This illustrated that the LEP receives a culture and a serum from the same patient only very rarely, thus demonstrating the importance of serology as a diagnostic tool.

The percentage of antibody-positive sera detected in this investigation $(31.5 \%)$ was considerably higher than levels obtained during previous studies in 1993 and 1996 (Thomas et al., 1993, 1996), where antibody-positive sera were detected in only $11 \%$ and $13 \%$ of patients, respectively. Since 1982 there has been an increase in the prevalence of E. coli O157 in England and Wales (Lynn et al., 2005; http://www.hpa.org.uk/infections/topics_az/ ecoli/O157/data_ew.htm), and this might explain the observed increase in the number of antibody-positive patients.

Age and gender were available for 506 of the 676 antibodypositive patients of which 221 were male (mean age $=13$ years 2 months \pm 18 years 1 month) and 285 were female (mean age $=14$ years 8 months \pm 19 years 9 months).

Examining the age structure of the 506 antibody-positive patients showed that the majority of patients $(66.4 \%)$ were 10 years of age or under (Table 1). An analysis of patients 
Table 1. Age distribution of patients with serum antibodies to E. coli $\mathrm{O} 157$

The numbers in parentheses in the top half of the table indicate the percentage of 506 patients; those in the bottom half of the table indicate the percentage of 337 children under the age of 10 years.

\begin{tabular}{|lc|}
\hline Age range (years) & No. $(\%)$ \\
\hline $0-10$ & $337(66.4)$ \\
$10.1-20$ & $90(17.8)$ \\
$20.1-30$ & $15(3.0)$ \\
$30.1-40$ & $16(3.2)$ \\
$40.1-50$ & $14(2.8)$ \\
$50.1-60$ & $9(1.8)$ \\
$60.1-70$ & $10(2.0)$ \\
$70.1-80$ & $10(2.0)$ \\
$80.1-90$ & $6(1.0)$ \\
$90.1-100$ & 0 \\
Total & 506 \\
& \\
$0-1$ & $18(5.3)$ \\
$1.1-2$ & $72(21.4)$ \\
$2.1-3$ & $46(13.6)$ \\
$3.1-4$ & $43(12.8)$ \\
$4.1-5$ & $41(12.2)$ \\
$5.1-6$ & $34(10.1)$ \\
$6.1-7$ & $18(5.3)$ \\
$7.1-8$ & $16(4.7)$ \\
$8.1-9$ & $25(7.4)$ \\
$9.1-10$ & $24(7.1)$ \\
Total & 337 \\
\hline
\end{tabular}

under the age of 10 years (Table 1) showed that the majority of patients were between the ages of 1 and 2 years. The majority of patients infected with E. coli $\mathrm{O} 157$ are reported as being 5 years of age or under (Bitzan et al., 1993; Rowe et al., 1993; Mead \& Griffin, 1998; Fitzpatrick, 1999; Havelaar et al., 2004; Lynn et al., 2005) and indeed 220 of the 337 patients in the present study were under the age of 5 (Table 1). A possible reason for most cases occurring in these younger age groups is that young children may be more prone to infections in general, since they have reduced immune experience. Younger children may also be prone to various infections due to poor hygiene, such as lack of hand-washing prior to consumption of food following contact with animals or animal faeces. Frequency of reporting may also contribute to this age effect, since parents are more likely to seek medical attention for very young children than for older patients.

\section{Serodiagnosis and patients' symptoms}

Symptoms of disease were provided for 372 of the 676 antibody-positive patients (Table 2). Strains of E. coli are recognized as the single most important cause of HUS (Levin \& Barratt, 1984; Thomas et al., 1993, 1996; Fitzpatrick, 1999; Karch et al., 2005; Lynn et al., 2005) and this was reflected in the occurrence of HUS (79.3\%) in antibody-positive patients involved in the present study. A prodrome of diarrhoea followed by HUS [typical $(\mathrm{D}+)$ HUS] was reported for only 24 of the antibody-positive patients. The 'typical' $(\mathrm{D}+)$ form of HUS has been described as the most frequently encountered clinical presentation for patients infected with E. coli O157 (Tarr et al., 2005) and yet the present investigation showed only $6.5 \%$ of antibody-positive patients as having 'typical HUS'. The majority $(79.3 \%)$ of antibody-positive patients had 'atypical' or (D-) HUS, suggesting that symptoms considered as characteristic of E. coli O157 infection might need to be redefined. However, it must be emphasized that the present study was based on clinical data submitted to the LEP with individual samples of sera and the data received would only reflect the symptoms at a given time. Changes in patients' symptoms during the entire disease process were not taken into consideration in our analysis but may have been considered in other studies relating cases of typical and atypical HUS.

\section{Patients' symptoms in relation to age}

The findings that within antibody-positive patients (Table 2) patients aged 10 years and under were more likely to present with diarrhoea, bloody diarrhoea, HUS, vomiting and/or pyrexia as compared with those over the age of 10 years suggests that younger children were more likely to develop these symptoms during an infection with VTEC O157. Although the reporting of diarrhoea was higher in the under 10 years of age group, diarrhoea was nevertheless reported for older age groups (Table 2).

\section{Serum antibodies binding to the R3 LPS core}

Detecting serum antibodies binding to the R3 core of E. coli LPS may indicate an infection with a strain of VTEC (Chart et al., 2002a), and since 2004, sera with antibodies binding to the R3 core LPS of E. coli O157, but not the O157 longchain LPS, have been tested against a panel of LPSs prepared from E. coli O26, O55, O103, O111, O128 and O145. In the 3-year period to November 2007, 67 sera were detected with antibodies to the R3 core and nine patients had antibodies to the LPS of serogroups of E. coli other than O157; these were E. coli O26 (4), O103 (2), O111 (1) and $\mathrm{O} 145$ (2). One patient had antibodies to the somatic antigens of both E. coli O26 and O103. Patients' serum antibodies to these E. coli serogroups have been reported previously (Chart \& Jenkins, 1999; Karch et al., 2005) and strains of E. coli belonging to serogroup O26 are an established cause of human illness (Robins-Browne, 1987; Scotland et al., 1990; Jenkins et al., 2008) but it appears that infections with strains belonging to serogroup O26 are rare.

Detecting serum antibodies binding to the R3 moiety of $E$. coli O157 core LPS proved to be a useful indicator of a putative human infection by a serogroup of E. coli other than O157, albeit in only a few cases. Since 2002, the LEP has received 11 sera with antibodies to the R3 region of LPS 
Table 2. Relationship between symptoms and age for 372 patients with serum antibodies to E. coli O157 LPS

\begin{tabular}{|c|c|c|c|c|c|c|c|}
\hline Age range (years) & Diarrhoea & Bloody diarrhoea & HUS & HUS + diarrhoea & Vomiting & Pyrexia & Fatal \\
\hline $0-10$ & 43 & 20 & 172 & 17 & 13 & 3 & 0 \\
\hline $10.1-20$ & 9 & 5 & 40 & 4 & 2 & 0 & 0 \\
\hline $20.1-30$ & 3 & 1 & 6 & 1 & 1 & 0 & 0 \\
\hline $30.1-40$ & 1 & 0 & 6 & 1 & 0 & 10 & \\
\hline $40.1-50$ & 4 & 2 & 4 & 1 & 0 & 1 & 0 \\
\hline $50.1-60$ & 4 & 2 & 2 & 1 & 1 & 0 & 1 \\
\hline $60.1-70$ & 1 & 2 & 1 & 0 & 0 & 0 & 0 \\
\hline $70.1-80$ & 3 & 1 & 5 & 1 & 1 & 0 & 0 \\
\hline $80.1-90$ & 1 & 0 & 0 & 0 & 1 & 0 & 1 \\
\hline $90.1-100$ & 0 & 0 & 0 & 0 & 0 & 0 & 0 \\
\hline $\mathrm{NK}^{*}$ & 22 & 15 & 59 & 0 & 3 & 0 & 0 \\
\hline Total $\dagger$ & $\begin{array}{c}91 \\
(24.5 \%)\end{array}$ & $\begin{array}{c}48 \\
(12.9 \%)\end{array}$ & $\begin{array}{c}295 \\
(79.3 \%)\end{array}$ & $\begin{array}{c}24 \\
(6.5 \%)\end{array}$ & $\begin{array}{c}22 \\
(5.9 \%)\end{array}$ & $\begin{array}{c}5 \\
(1.3 \%)\end{array}$ & $\begin{array}{c}2 \\
(0.5 \%)\end{array}$ \\
\hline
\end{tabular}

${ }^{\star}$ Age not known.

$\dagger$ Numbers in parentheses are the percentage of 372 .

core but without antibodies to the long-chain LPS from $E$. coli $\mathrm{O} 26, \mathrm{O} 55, \mathrm{O} 103, \mathrm{O} 111, \mathrm{O} 128$ or $\mathrm{O} 145$. The various core regions of E. coli and Salmonella species have been described (Heinrichs et al., 1998; Amor et al., 2000) but how widespread the R3 core moiety is in other members of the Enterobacteriaceae is unknown and so the cause of disease in the 11 patients remained unresolved.

\section{Serodiagnosis of VTEC 0157 infections}

Although the detection of serum antibodies to the LPS of E. coli $\mathrm{O} 157$ provides evidence of a putative infection with VTEC O157, apparently healthy people may also have serum antibodies to the $\mathrm{O} 157$ somatic antigens. For example, a study of sera from members of rural communities in England showed that people with occupational exposure to cattle had antibodies to the LPS of $E$. coli $\mathrm{O} 157$ and/or to verocytotoxin (Evans et al., 2000). In contrast, a study screening sera from healthy blood donors failed to detect people with serum antibodies to E. coli O157 LPS (Jenkins \& Chart, 1999a).

The results of serodiagnosis must also be considered in the light of known antibody-antigen cross-reactions. Strains of E. coli O157 share LPS epitopes with Brucella abortus (Chart et al., 1992), Yersinia enterocolitica O9 (Chart et al., 1991), Vibrio cholerae O1 Inaba and strains of Salmonella spp. belonging to serogroup N (Chart et al., 1993). The possible involvement of these organisms in cases of disease must be borne in mind. Although the symptoms of diseases caused by B. abortus, Y. enterocolitica O9, V. cholerae $\mathrm{O} 1$ Inaba and group $\mathrm{N}$ Salmonella are unlikely to be confused with those of O157 VTEC, this emphasizes the importance of having knowledge of patients' clinical details.

Problems with serodiagnosis can also occur when patients with HUS undergo renal dialysis and/or receive blood transfusions, since both of these procedures are known to reduce the levels of serum antibodies to E. coli O157 LPS (H. Chart, unpublished). Where clinical details indicate that patients have received either renal dialysis and/or blood transfusions, or had undergone plasma exchange, a second serum sample taken later in the pathogenesis of disease may often demonstrate antibodies to E. coli O157 LPS (H. Chart, unpublished) and so facilitate diagnosis. Patients' serum antibodies to E. coli O157 LPS may persist for many months post-infection, so serodiagnosis of infections with E. coli O157 and other VTEC continues to provide an important adjunct to bacteriology. Where clinicians suspect the involvement of a VTEC in cases of human disease and particularly in cases of HUS, patients' sera should be submitted to the LEP for analysis without delay.

\section{REFERENCES}

Amor, K., Heinrichs, D. E., Frirdich, E., Ziebell, K., Johnson, R. P. \& Whitfield, C. (2000). Distribution of core oligosaccharide types in lipopolysaccharides from Escherichia coli. Infect Immun 68, 11161124.

Bitzan, M., Ludwig, K., Klemt, M., König, H., Büren, J. \& Müller-Wiefel, D. E. (1993). The role of Escherichia coli O 157 infections in the classical (enteropathic) haemolytic uraemic syndrome: results of a Central European, multicentre study. Epidemiol Infect 110, 183-196.

Chart, H. (2000). Clinical significance of Verocytotoxin-producing Escherichia coli serotype O157. World J Microbiol Biotechnol 16, 719-724.

Chart, H. (2003). The pathogenicity of strains of Salmonella paratyphi B and Salmonella java. J Appl Microbiol 94, 340-348.

Chart, H. \& Jenkins, C. (1998). Salivary antibodies to lipopolysaccharide antigens of Escherichia coli serotype O157. Lancet 352, 371.

Chart, H. \& Jenkins, C. (1999). Serodiagnosis of infections caused by verocytotoxin-producing Escherichia coli. J Appl Microbiol 86, 731-740.

Chart, H., Scotland, S. M. \& Rowe, B. (1989). Serum antibodies to Escherichia coli serotype O157:H7 in patients with hemolytic uremic syndrome. J Clin Microbiol 27, 285-290. 
Chart, H., Cheasty, T., Cope, D., Gross, R. J. \& Rowe, B. (1991). The serological relationship between Yersinia enterocolitica O9 and Escherichia coli $\mathrm{O} 157$ using sera from patients with yersiniosis and haemolytic uraemic syndrome. Epidemiol Infect 107, 349-356.

Chart, H., Okubadejo, O. A. \& Rowe, B. (1992). The serological relationship between Escherichia coli $\mathrm{O} 157$ and Yersinia enterocolitica O9 using sera from patients with brucellosis. Epidemiol Infect 108, 77-85.

Chart, H., Cheasty, T., Giorgio, T. \& Rowe, B. (1993). Antigenic crossreactions between Escherichia coli O157, Vibrio cholerae O1 Inaba and group N Salmonella. Serodiag Immunother Inf Dis 5, 81-84.

Chart, H., Cheasty, T. \& Willshaw, G. A. (2002a). Production of serum antibodies that recognise epitopes located on the R3 region of Escherichia coli core lipopolysaccharides in patients infected with strains of enterohaemorrhagic E. coli. J Med Microbiol 51, 1050-1054.

Chart, H., Perry, N. T., Cheasty, T. \& Wright, P. A. (2002b). The kinetics of antibody production to antigens of Escherichia coli O157 in a pregnant woman with haemolytic uraemic syndrome. J Med Microbiol 51, 522-525.

Chart, H., Perry, N. T., Willshaw, G. A. \& Cheasty, T. (2003). Analysis of saliva for antibodies to the LPS of Escherichia coli O157 in patients with serum antibodies to E. coli O157 LPS. J Med Microbiol 52, 569572.

Chart, H., Perry, N. T. \& Jenkins, C. (2004). The expression of an R3 lipopolysaccharide-core by pathotypes of Escherichia coli. J Appl Microbiol 96, 982-986.

Dalwai, F. \& Chart, H. (2003). Human antibody responses to R3-core epitopes on the lipopolysaccharide of Escherichia coli O157. Lett Appl Microbiol 37, 429-432.

Evans, J., Chalmers, R. M., Chart, H., Salmon, R. L., Kench, S. M., Coleman, T. J., Meadows, D., Morgan-Capner, P., Softley, P. \& other authors (2000). Evidence of persisting serum antibodies to Escherichia coli O157 lipopolysaccharide and Verocytotoxin in members of rural communities in England. Eur J Epidemiol 16, 885-889.

Fitzpatrick, M. (1999). Haemolytic uraemic syndrome and E. coli O157 - prevention rests with sound public health measures. BMJ 318, 684-685.

Havelaar, A. H., Van Duynhoven, Y. T., Nauta, M. J., Bouwknegt, M., Heuvelink, A. E., De Wit, G. A., Nieuwenhuizen, M. G. \& van de Kar, N. C. (2004). Disease burden in The Netherlands due to infections with Shiga toxin-producing Escherichia coli O157. Epidemiol Infect 132, 467-484.

Heinrichs, D. E., Yethon, J. A. \& Whitfield, C. (1998). Molecular basis for structural diversity in the core regions of the lipopolysaccharides of Escherichia coli and Salmonella enterica. Mol Microbiol 30, 221-232.
Jenkins, C. \& Chart, H. (1999a). Antibodies to lipopolysaccharides of Escherichia coli serogroups O5 and O165 in healthy adults. Lancet 354, 649.

Jenkins, C. \& Chart, H. (1999b). Serodiagnosis of infection with verocytotoxin-producing Escherichia coli serogroups. J Appl Microbiol 86, 569-575.

Jenkins, C., Evans, J., Chart, H., Willshaw, G. A. \& Frankel, G. (2008). Escherichia coli serogroup O26 - a new look at an old adversary. J Appl Microbiol 104, 14-25.

Karch, H., Tarr, P. I. \& Bielaszewska, M. (2005). Enterohaemorrhagic Escherichia coli in human medicine. Int J Med Microbiol 295, 405-418.

Karmali, M. A., Petric, M., Lim, C., Fleming, P. C., Arbus, G. S. \& Lior, H. (1985). The association between idiopathic hemolytic uremic syndrome and infection by verotoxin-producing Escherichia coli. $J$ Infect Dis 151, 775-782.

Laemmli, U. K. (1970). Cleavage of structural proteins during the assembly of the head of bacteriophage T4. Nature 227, 680-685.

Levin, M. \& Barratt, T. M. (1984). Haemolytic uraemic syndrome. Arch Dis Child 59, 397-400.

Lynn, R. M., O'Brien, S. J., Taylor, C. M., Adak, G. K., Chart, H., Cheasty, T., Coia, J. E., Gillespie, I. A., Locking, M. E. \& other authors (2005). Childhood hemolytic uremic syndrome, United Kingdom and Ireland. Emerg Infect Dis 11, 590-596.

Mead, P. S. \& Griffin, P. M. (1998). Escherichia coli serotype O157 : H7. Lancet 352, 1207-1212.

Robins-Browne, R. M. (1987). Traditional enteropathogenic Escherichia coli of infantile diarrhea. Rev Infect Dis 9, 28-53.

Rowe, P. C., Orrbine, E., Lior, H., Wells, G. A. \& McLaine, P. N. (1993). A prospective study of exposure to verotoxin-producing Escherichia coli among Canadian children with haemolytic uraemic syndrome. Epidemiol Infect 110, 1-7.

Scotland, S. M., Willshaw, G. A., Smith, H. R. \& Rowe, B. (1990). Properties of strains of Escherichia coli O26:H11 in relation to their enteropathogenic or enterohemorrhagic classification. J Infect Dis 162, 1069-1074.

Tarr, P. I., Gordon, C. A. \& Chandler, W. L. (2005). Shiga-toxinproducing Escherichia coli and haemolytic uraemic syndrome. Lancet 365, 1073-1086.

Thomas, A., Chart, H., Cheasty, T., Smith, H. R., Frost, J. A. \& Rowe, B. (1993). Vero cytotoxin-producing Escherichia coli, particularly serogroup O 157, associated with human infections in the United Kingdom: 1989-91. Epidemiol Infect 110, 591-600.

Thomas, A., Cheasty, T., Frost, J. A., Chart, H., Smith, H. R. \& Rowe, B. (1996). Vero cytotoxin-producing Escherichia coli, particularly serogroup O157, associated with human infections in the United Kingdom: 1992-4. Epidemiol Infect 117, 1-10. 